\title{
Intracellular lipid metabolism impairs $\beta$ cell compensation during diet-induced obesity
}

\author{
Risheng Ye, ${ }^{1,2}$ Ruth Gordillo, ${ }^{1}$ Mengle Shao, ${ }^{1}$ Toshiharu Onodera, ${ }^{1}$ Zhe Chen, ${ }^{1,3}$ Shiuhwei Chen, ${ }^{1}$ Xiaoli Lin, ${ }^{1}$ Jeffrey A. SoRelle, ${ }^{3}$ \\ Xiaohong Li, ${ }^{3}$ Miao Tang, ${ }^{3}$ Mark P. Keller, ${ }^{4}$ Regina Kuliawat, ${ }^{5}$ Alan D. Attie, ${ }^{4}$ Rana K. Gupta, ${ }^{1}$ William L. Holland, ${ }^{1}$ Bruce Beutler, ${ }^{3}$ \\ Joachim Herz, ${ }^{6,7}$ and Philipp E. Scherer ${ }^{1}$

\begin{abstract}
${ }^{1}$ Touchstone Diabetes Center, Department of Internal Medicine, University of Texas Southwestern (UTSW) Medical Center, Dallas, Texas, USA. ²Department of Medical Education, Texas Tech University Health Sciences Center Paul L. Foster School of Medicine, El Paso, Texas, USA. ${ }^{3}$ Center for the Genetics of Host Defense, UTSW Medical Center, Dallas, Texas, USA. ${ }^{4}$ Department of Biochemistry, University of Wisconsin, Madison, Wisconsin, USA. ${ }^{5}$ Department of Developmental and Molecular Biology, Albert Einstein College of Medicine, New York, New York, USA ${ }^{6}$ Departments of Molecular Genetics, Neuroscience, Neurology and Neurotherapeutics, and Center for Translational Neurodegeneration Research, UTSW Medical Center, Dallas, Texas, USA. ${ }^{7}$ Center for Neuroscience, Department of Neuroanatomy, Albert Ludwig University, Freiburg, Germany.
\end{abstract}

\begin{abstract}
The compensatory proliferation of insulin-producing $\beta$ cells is critical to maintaining glucose homeostasis at the early stage of type 2 diabetes. Failure of $\beta$ cells to proliferate results in hyperglycemia and insulin dependence in patients. To understand the effect of the interplay between $\beta$ cell compensation and lipid metabolism upon obesity and peripheral insulin resistance, we eliminated LDL receptor-related protein 1 (LRP1), a pleiotropic mediator of cholesterol, insulin, energy metabolism, and other cellular processes, in $\beta$ cells. Upon high-fat diet exposure, LRP1 ablation significantly impaired insulin secretion and proliferation of $\beta$ cells. The diminished insulin signaling was partly contributed to by the hypersensitivity to glucoseinduced, $\mathrm{Ca}^{2+}$-dependent activation of Erk and the mTORC1 effector p85 S6K1. Surprisingly, in LRP1-deficient islets, lipotoxic sphingolipids were mitigated by improved lipid metabolism, mediated at least in part by the master transcriptional regulator PPAR $\gamma 2$. Acute overexpression of PPAR $\gamma 2$ in $\beta$ cells impaired insulin signaling and insulin secretion. Elimination of Apbb2, a functional regulator of LRP1 cytoplasmic domain, also impaired $\beta$ cell function in a similar fashion. In summary, our results uncover the double-edged effects of intracellular lipid metabolism on $\beta$ cell function and viability in obesity and type 2 diabetes and highlight LRP1 as an essential regulator of these processes.
\end{abstract}

\section{Introduction}

At early stages of type 2 diabetes, $\beta$ cells increase insulin production by hyperplasia as a compensatory response to insulin resistance in peripheral tissues (1). At that stage, the systemic glucose homeostasis remains intact until, at later stages, $\beta$ cell failure and frank diabetes ensue. Therefore, maintenance of adequate $\beta$ cell volume and function is key to managing patients with impaired fasting glucose and/or glucose tolerance. Insulin signaling in $\beta$ cells plays a major role in their volume and functional compensation to diet-induced obesity (DIO) and peripheral insulin resistance $(1,2)$. However, the regulatory mechanism or mechanisms by which $\beta$ cell insulin signaling is homeostatically maintained remain unclear.

During DIO, the most prevalent cause of type 2 diabetes, $\beta$ cell viability is challenged by glucolipotoxicity (3) through cytotoxic metabolites or signaling that results from high levels of glucose and fatty acids. Both of these classes of nutrients can ultimately be converted into ceramides, a class of lipotoxic sphingolipids that promote $\beta$ cell apoptosis (4). We have previously shown that improvements in systemic (5) and intracellular (6) lipid metabo-

Conflict of interest: The authors have declared that no conflict of interest exists. Submitted: September 27, 2017; Accepted: January 9, 2018

Reference information: / Clin Invest. 2018;128(3):1178-1189.

https://doi.org/10.1172/JCI97702 lism reduce lipotoxicity and promote $\beta$ cell regeneration in type 1 diabetes. Here, we set out to investigate the role of lipid metabolism in $\beta$ cell function in the context of DIO and type 2 diabetes.

LDL receptor-related protein 1 (LRP1) is a member of the LDL receptor family $(7,8)$. As a transmembrane protein, LRP1 consists of multiple extracellular ligand-binding repeats and $\mathrm{Ca}^{2+}$-binding domains and binds to a variety of ligands, such as apolipoprotein $\mathrm{E}$ (apoE), $\alpha 2 \mathrm{M}$, and PDGF $\beta$. Highly diverse functions of LRP1 have been reported in different tissues. For example, LRP1 is a major suppressor of aneurysm formation and atherosclerosis in vascular smooth muscle (9) and supports glucose and lipid metabolism in neurons $(10,11)$ and adipose tissue $(12)$ as well as liver $(13,14)$. However, the mechanistic role or roles and impact on cellular physiology of LRP1 receptors in $\beta$ cells have not been addressed.

In this study, we wanted to define LRP1 as a potential modulator of lipid metabolism in $\beta$ cells. In B6:BTBR F2 ${ }^{o b / o b}$ mice, islet $L r p 1$ mRNA levels correlate negatively with fasting plasma insulin, glucose, and triglycerides. However, when we knocked out LRP1 specifically in mature $\beta$ cells, the mice exhibited surprising decreases in $\beta$ cell volume and glucose-stimulated insulin secretion (GSIS) during DIO. LRP1-deficient $\beta$ cells are less proliferative and show lower insulin production, with impaired insulin signaling. They are hypersensitive to glucose-induced, $\mathrm{Ca}^{2+}$-dependent activation of Erk and the mTORC1 effector p85 S6K1, which eventually leads 


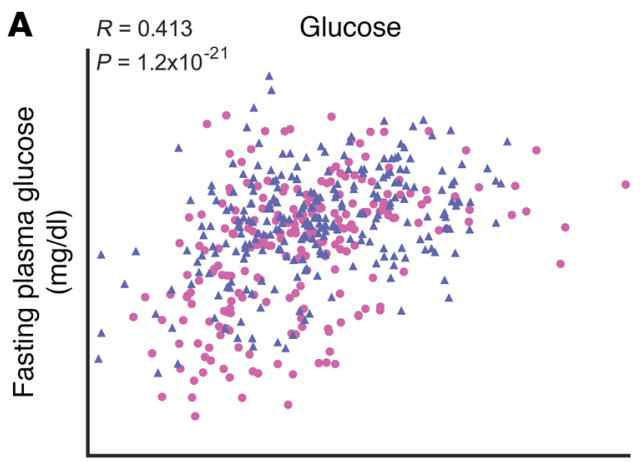

Islet $\operatorname{Lrp1}\left(\log _{10}\right.$ Intensity $)$

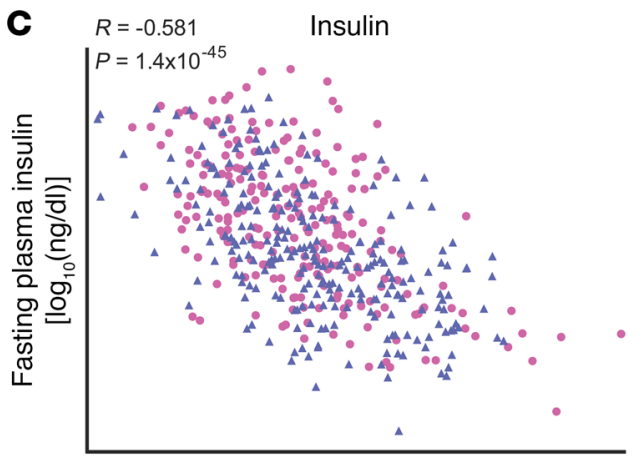

Islet Lrp1 ( $\log _{10}$ Intensity)

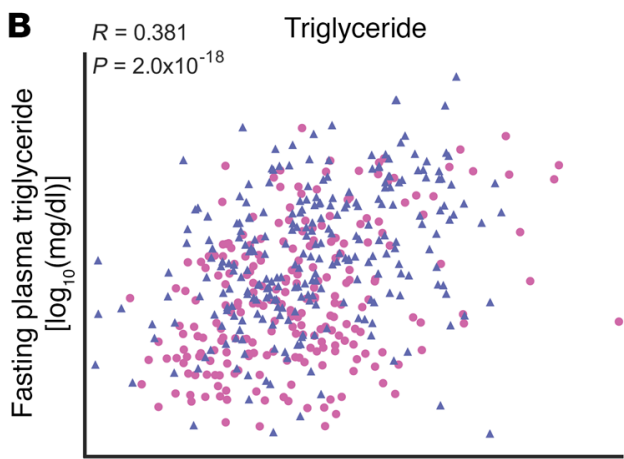

Islet $\operatorname{Lrp1}\left(\log _{10}\right.$ Intensity)
$\Delta$ Male

- Female to insulin receptor substrate 2 (IRS-2) reduction. More surprisingly, LRP1-KO $\beta$ cells alleviate lipotoxicity by improvements in lipid metabolism, as evidenced by upregulation of lipid enzymes and the key transcription factor PPAR $\gamma 2$. Overexpression of PPAR $\gamma 2$ in $\beta$ cells directly reveals that intracellular lipid metabolism impairs $\beta$ cell insulin signaling and GSIS during DIO. Ablation of Apbb2, a functional modulator of the cytoplasmic domain of LRP1, also leads to $\beta$ cell dysfunction and systemic glucose intolerance. Collectively, our findings suggest a mechanism of glucolipotoxicity in $\beta$ cells, i.e., that the adaptive signaling pathways combating high glucose and lipids can contribute to the eventual $\beta$ cell failure in type 2 diabetes, and highlight LRP1 as an essential modulator of such double-edged adaptations.

\section{Results}

Islet Lrp1 expression correlates with diabetes-related phenotypes. To determine whether LRP1 plays a role in $\beta$ cell function and glucose metabolism, we analyzed islet $\operatorname{Lrp} 1$ transcript abundance in a large population of genetically obese (Leptin ${ }^{o b / o b}$ ) B6:BTBR F2 mice (15). Islet LRP1 correlates positively with plasma glucose $(R=0.413$, $P=1.2 \times 10^{-21}$, Figure $\left.1 \mathrm{~A}\right)$ and triglyceride $\left(R=0.381, P=2.0 \times 10^{-18}\right.$, Figure $1 \mathrm{~B})$ and negatively with plasma insulin $(R=-0.581, P=1.4 \times$ $10^{-45}$, Figure $1 C$ ). These results demonstrate that the genetic regulation of islet LRP1 is associated with a dysregulation of glucose homeostasis. However, the scatter in the population was significant. To probe for the relative contribution of LRP1 to the cellular homeostasis and responsiveness to glucose more directly, we decided to use a genetic approach to manipulate islet LRP1 levels and determine whether this association reflects a direct causal relationship between LRP1 and islet function.
Figure 1. Lrp1 gene transcription negatively correlates with $\beta$ cell function in B6:BTBR F2 ${ }^{\text {ob/ob }}$ mice. Pancreatic islets were isolated from individual 10-week-old, chow-fed B6:BTBR F2 ${ }^{o b / o b}$ mice $(n=491)$, prepared for RNA, and subjected to microarray analysis of gene expression. The Lrp1 mRNA level is correlated to fasting plasma glucose (A), triglyceride (B) and insulin (C). To approximate normal distribution, $\log _{10}$ transformation was applied to the expression values for $L r p 1$ as well as the measurements of triglyceride and insulin. Data normality was tested by Kolmogorov-Smirnov test with Lilliefors correction. Correlation coefficients $R$ and $P$ values were calculated by the Pearson product moment test.

LRP1 is required for compensatory $\beta$ cell hyperplasia and glucose metabolism in HFD-fed mice. To directly investigate the physiological role of LRP1 in the insulin-producing $\beta$ cell, we generated $\operatorname{Lrp1}-\beta K O$, a mouse model allowing doxycyclineinducible (Tet-On), $\beta$ cell-specific elimination of the $L r p 1$ gene (Figure 2A). In the Lrp1- $\beta K O$ mice, homozygous $L r p 1$ floxed alleles $\left(\operatorname{Lrp} 1^{f / f l}\right)(16)$ were crossed with the transgenes reverse tetracycline transactivator ( $r T T A)(17)$ and TRE-Cre. Expression of the rtTA protein is driven by the mouse insulin promoter $(M I P)$ and thus exclusively active in $\beta$ cells. In the presence of doxycycline, the rtTA protein activates the tetracycline response element-controlled (TRE-controlled) promoter and thus the local expression of Cre recombinase, which irreversibly converts the $L r p 1$ floxed alleles into $\mathrm{KO}$ alleles $\left(L r p 1^{-/}\right)$in all mature $\beta$ cells. Littermates lacking the TRE-Cre transgene were employed as the control group. Both $\operatorname{Lrp1}-\beta K O$ and control mice were first fed a doxycycline-containing diet for 2 weeks and then switched to regular chow diet (RD) or high-fat diet (HFD) (Figure 2A). Compared with what occurred in the control mice, elimination of LRP1 was evident in the isolated pancreatic islets of Lrp1- $\beta K O$ mice at both mRNA (Figure 2B) and protein levels (Figure 2C). LRP1 depletion in $\beta$ cells was further confirmed by immunofluorescence (Supplemental Figure 1A; supplemental material available online with this article; https:// doi.org/10.1172/JCI97702DS1).

Surprisingly, Lrp1- $\beta K O$ mice on RD showed a trend toward glucose intolerance compared with controls (Figure 2D). After HFD, while the control mice still maintained relatively normal glucose tolerance, $\operatorname{Lrp1-\beta KO}$ mice were significantly ineffective with respect to glucose disposal. HFD-fed control mice showed the 
A
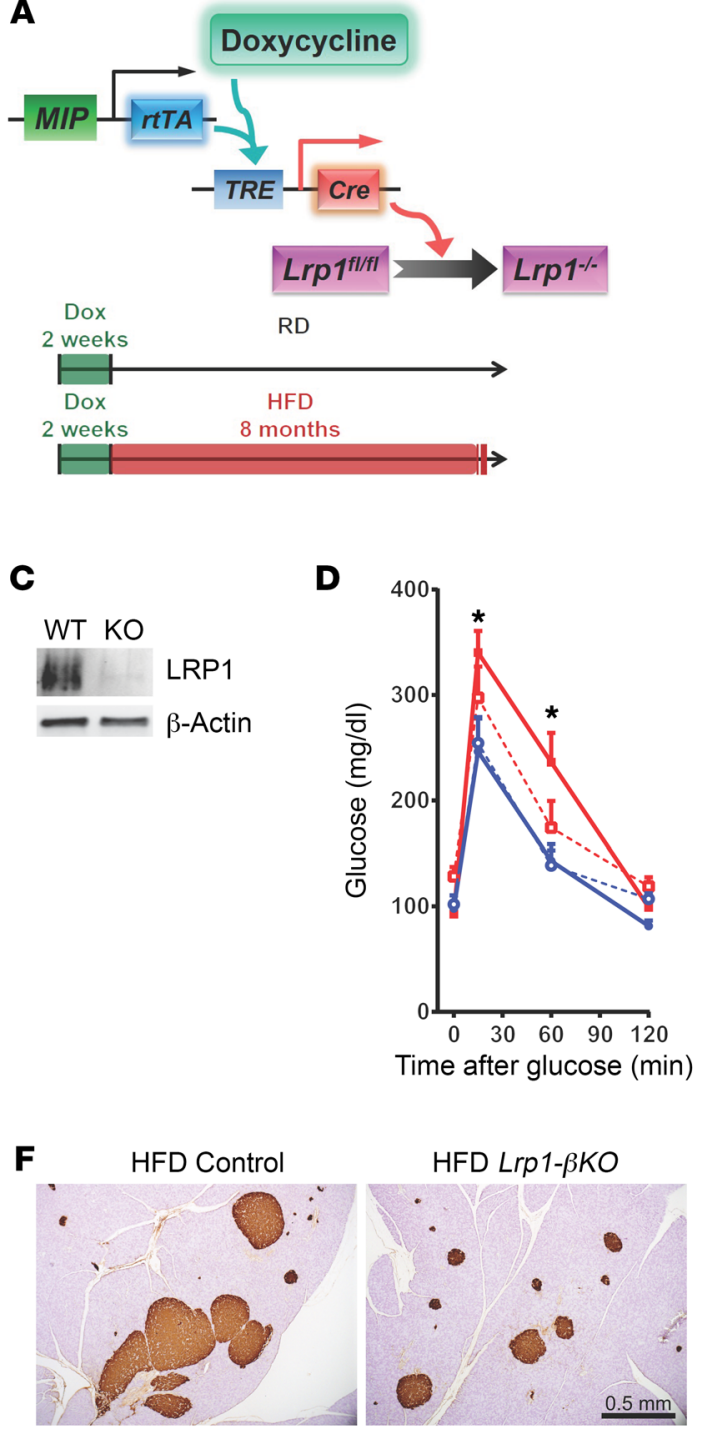

B
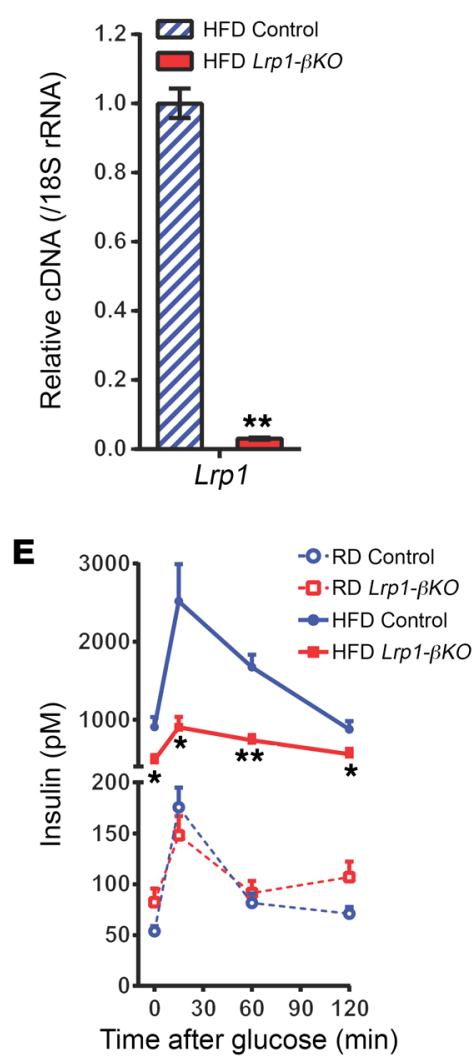

G

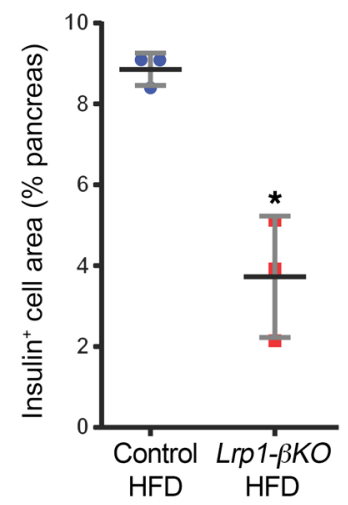

Figure 2. LRP1 ablation prevents $\beta$ cell compensation during DIO. (A) Doxycyclineinducible $K O$ of $L r p 1$ in mouse $\beta$ cells. In Lrp1- $\beta K O$ mice with the genotype MIP-rtTA TRE-Cre; $L r p 1^{f l / f 1}$, the transgene MIP-rtTA expresses an rtTA specifically in $\beta$ cells. In the presence of doxycycline (Dox), rtTA activates the transcription of the TRE-Cre transgene. The Cre recombinase in turn converts the Lrp1 floxed alleles to KO (-) alleles. After 2 weeks of doxycycline diets, both $L r p 1-\beta K O$ and control mice were fed on RD or HFD for up to 8 months. (B and $\mathbf{C}$ ) Pancreatic islets were isolated from HFD-fed mice and subjected to RT-qPCR (B) or Western blotting (C) for LRP1 expression. (D and $\mathbf{E}$ ) Six months after doxycycline treatment, mice were subjected to oral glucose tolerance test $(2 \mathrm{mg} / \mathrm{g}$ body weight) and measured for plasma glucose (D) and insulin (E). $n=5-7$ mice per condition. ( $\mathbf{F}$ and $\mathbf{G})$ Pancreas sections of mice after 8 months of HFD were immunostained for insulin (F), and the stained areas (brown) were normalized against total pancreas area in individual mice (G). Data are presented as mean \pm SEM. ${ }^{*} P<0.05 ;{ }^{* *} P<0.01$ for Lrp1$\beta K O$ versus control mice by 2 -tailed unpaired Student's $t$ test. expected increase in GSIS, thereby supporting the maintenance of normal glucose metabolism (Figure 2E). However, the compensatory increase in $\beta$ cell output was largely diminished in the absence of LRP1. The reduction in insulin was the primary cause of the glucose intolerance in HFD-fed $\operatorname{Lrp} 1-\beta K O$ mice because they were even more insulin sensitive than the control group during an insulin tolerance test (Supplemental Figure 1B). Meanwhile the differences in body weight, fat mass, and lean mass were not significant between the 2 groups (Supplemental Figure 1C).

The defective insulin production in HFD-fed Lrp1- $\beta$ KO mice was associated with a more than $50 \%$ decrease in $\beta$ cell volume compared with controls (Supplemental Figure 1D, and Figure 2, F and G). Quantitation of individual islet size in these animals revealed that the $L r p 1-\beta K O$ islets were less hyperplasic (Supplemental Figure 1E). BrdU incorporation suggested LRP1 is critical for $\beta$ cell proliferation under both $\mathrm{RD}$ and HFD regimens (Figure 3 , A and B). And we observed reduced expression of cell-cycle regulators cyclin A2 and Mdm2, a mediator of p53 degradation (18) (Supplemental Figure 2A).

To further understand the role of LRP1 in $\beta$ cell function, we examined the intracellular structure by electron microscopy (Figure 3, C and D) and found more immature secretory granules in Lrp1-KO $\beta$ cells. This phenotype can be attributed, at least in part, to the reduced expression of the insulin 1 gene (Figure $3 \mathrm{E})$. In isolated $\operatorname{Lrp1}-\beta K O$ islets, we also observed significant reduction in Tcf7l2 (19), $P d x 1$ (20), and Neurod1 (21) mRNAs, key transcription factors for insulin expression and $\beta$ cell proliferation (Figure 3E). There was no significant change in the mRNAs of insulin processing (Supplemental Figure 2B) or endoplasmic reticulum (ER) stress-signaling genes (Supplemental Figure 2C), 
A
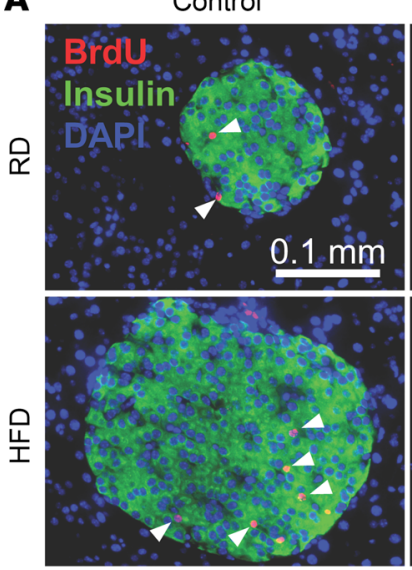

B

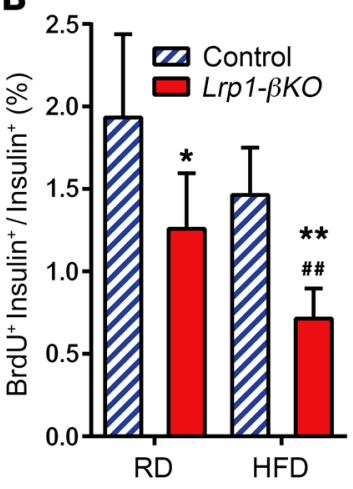

Lrp1-ßKO

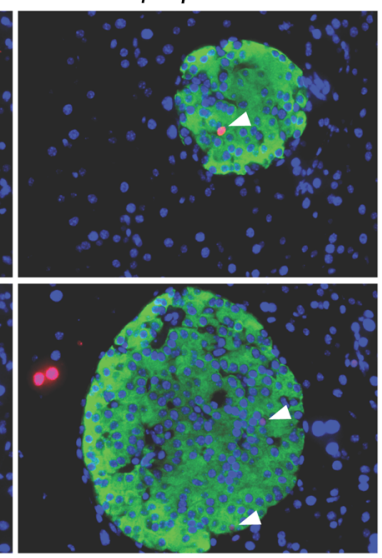

C

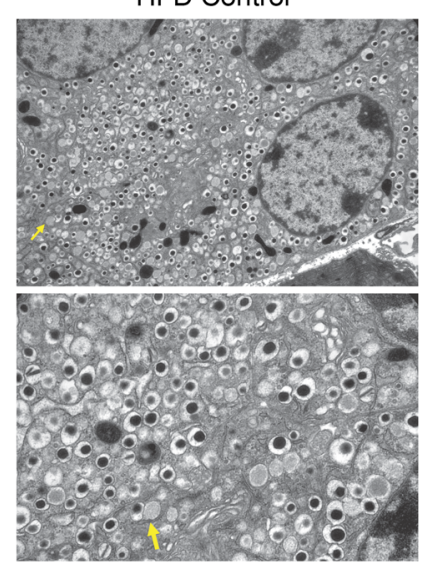

HFD Lrp1- $\beta K O$

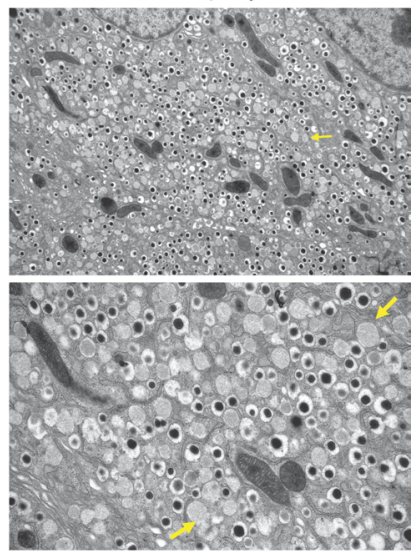

D

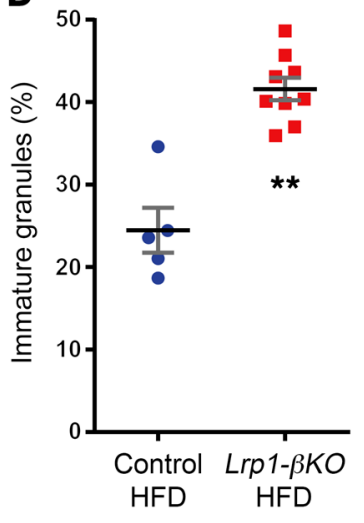

E

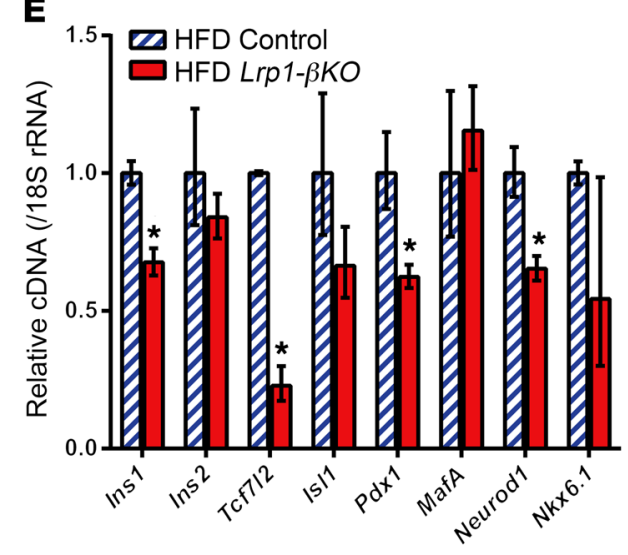

Figure 3. Defective proliferation and insulin production in LRP1-KO $\beta$ cells after HFD. (A and B) Four months after doxycycline treatment, mice were subjected to 3 consecutive daily i.p. injections of BrdU, and their pancreas sections were subjected to immunofluorescence of BrdU (red), merged with insulin (green) and DAPI (blue). (A) Representative images. Arrowheads show examples of BrdU-positive $\beta$ cells. (B) Percentage of BrdU-positive $\beta$ cells. $n=2.8-8.1$ $\times 10^{3}$ cells (31-48 islets) per condition. Data are presented as percentage $\pm 95 \% \mathrm{Cl}$. ${ }^{*} P<0.05 ;{ }^{* *} P<0.01$ for $L r p 1-\beta K O$ versus control mice; ${ }^{\# \# P}<0.01$ for RD versus HFD by $Z$ test. (C and D) Transmission electron microscopy of $\beta$ cells in mice after 8 months of HFD. (C) Representative fields. Original magnification, $\times 10,000$ (upper panels); $\times 25,000$ (lower panels). Arrows show examples of immature secretory granules. (D) Percentage of granules lacking an electron-dense core. $n=5$ (control); $n=9$ (Lrp1- $\beta K O) \times 25,000$ fields, with $75-220$ granules per field. (E) RT-qPCR of insulin and $\beta$ cell transcription factors with pancreatic islets from mice after 8 months of HFD. $n=3$ to 4 mice per genotype. Data are presented as mean \pm SEM. ${ }^{*} P<0.05$; ${ }^{* *} P<0.01$ for $L$ rp $1-\beta K O$ versus control mice by 2-tailed unpaired Student's $t$ test.

downplaying the role of posttranslational regulation in insulin deficiency. In summary, these results demonstrate that LRP1 is required for the compensatory proliferation and insulin production of $\beta$ cells upon HFD.

$L R P 1$ regulates the insulin signaling pathway in $\beta$ cells. We further investigated the insulin-signaling cascades in islets, since these pathways are well-established key regulators of $\beta$ cell function and proliferation, especially for compensation to DIO and insulin resistance (2). While there is always plenty of insulin available locally, tonic insulin signaling is crucial for proper $\beta$ cell functionality. At the mRNA level, we observed a significant reduction in IRS- 1 and -2 as well as the glucose transporter Glut2 upon LRP1 ablation (Figure 4A). There was also a trend toward reduction $(P=0.06)$ in Gck expression, consistent with a defective insulin-signaling pathway in islets lacking LRP1. At the protein level, $L r p 1-\beta K O$ islets from RD-fed mice showed a significant decrease in IRS-2 (Figure 4B and Supplemental Figure 3, A-D). HFD resulted in potent activation of insulin signaling in control islets, consistent with their compensatory upregulation in $\beta$ cell volume and insulin production. However, insulin-signaling components, including IR $\beta$, IRS-2, and phosphorylated Akt, were moderately diminished when LRP1 was absent. The dramatic reduction in IR $\beta$ was further confirmed by immunofluorescence (Figure 4, $\mathrm{C}$ and $\mathrm{D})$. Therefore, $\mathrm{LRP1}$ is required to mediate proper compensatory insulin signaling in $\beta$ cells in response to HFD.

We wanted to understand how $\beta$ cell insulin signaling is regulated by LRP1. In the context of obesity, the phosphorylated, active form of CREB is implicated as a key transcription activator linking glucose metabolism with cAMP amplification, thereby triggering the induction of IRS-2 and cell-cycle regulators in $\beta$ cells (1). LRP1 ablation led to a reduction in CREB levels; however, this was only seen in RD-fed animals, not in the HFD-fed cohort (Supplemental Figure 3, E and F). CREB seems therefore an unlikely candidate to be responsible for the impaired insulin signaling in the HFD setting.

The mTORC1 signaling pathway is activated by the insulinAkt cascade and mediates cell growth (22). HFD did induce phosphorylation of the S6 kinase 1 (S6K1) p85 isoform, a direct indica- 


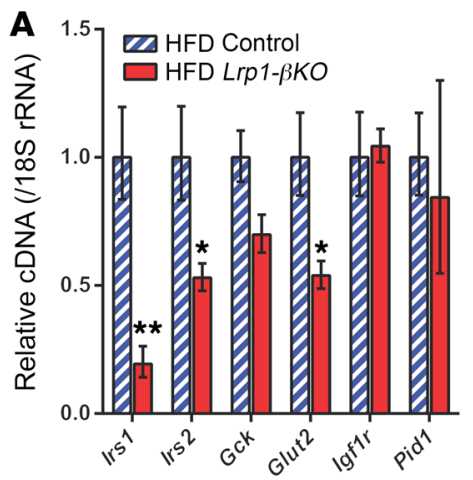

B
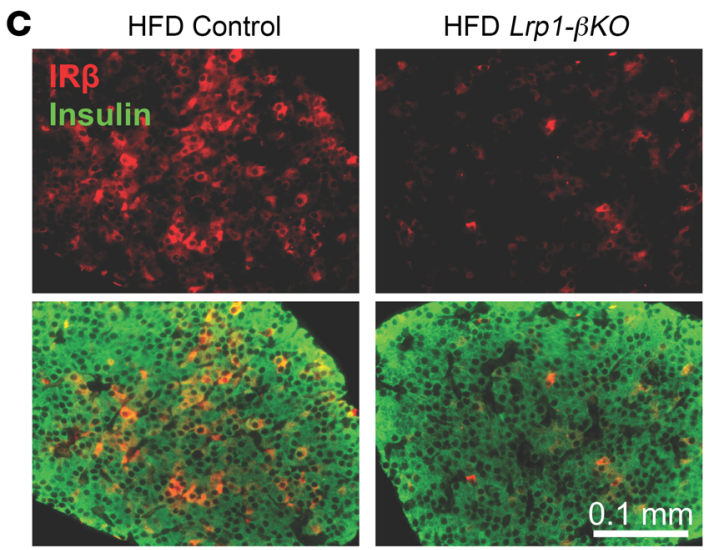

D

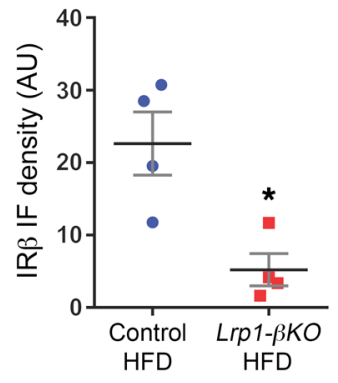

Figure 4. Diminished insulin signaling in Lrp1- $\beta K O$ islets after HFD. Experiments used mice 8 months after doxycycline treatment. (A) RT-qPCR of insulin/ IGF signaling genes with pancreatic islets. $n=3$ to 4 mice per genotype. (B) Representative Western blots of insulin-signaling molecules with pancreatic islets. Noncontiguous lanes run on the same gel are separated by black lines. (C and $\mathbf{D}$ ) Immunofluorescence of IR $\beta$ on pancreas sections. (C) Representative images. Upper panels: IR $\beta$ signal (red) only. Lower panels: merged with insulin (green). (D) IR $\beta$ signal intensity in insulin-positive cells is quantitated in individual mice (4-6 $\times 20$ sections per mouse). Data are presented as mean \pm SEM. ${ }^{*} P<0.05 ;{ }^{* *} P<0.01$ for $L r p 1-\beta K O$ versus control mice by 2 -tailed unpaired Student's $t$ test. tor of mTORC1 activation, in control islets (Figure 5A), consistent with enhanced insulin signaling (Figure $4 \mathrm{~B}$ and Supplemental Figure 3, A-D). However, to our surprise, Lrp1- $\beta K O$ islets after HFD exhibited a paradoxical increase in p85 S6K1 phosphorylation (Figure 5A and Supplemental Figure 4, A-D). Such changes did not fully transmit to S6 phosphorylation (Figure 5A and Supplemental Figure 4E), which depends primarily on S6K2 or p70 S6K1 (23-25). Instead, S6K1 activation can contribute, at least in part, to the suppression of IRS-2 as feedback inhibition (26) and, eventually, the failureof $\beta$ cells to compensate $(27,28)$.

To explain the paradoxical induction of mTORC1 associated with reduced insulin signaling in $L r p 1-\beta K O$ islets after HFD, we examined the activation of Erk, which may be an alternate activator of mTORC1, independent of Akt $(29,30)$. The levels of phosphorylated Erk were consistent with S6K1 phosphorylation in islets (Figure 5B and Supplemental Figure 4F). In vascular smooth muscle cells, LRP1 ablation led to dramatic induction of PDGFR $\beta$ and Erk activation (9). However, PDGFR $\beta$ induction was minor in Lrp1- $\beta$ KO islets after HFD (Supplemental Figure 7, A and B). In cultured mouse islets, 15 minutes of high glucose treatment in the absence of exogenous insulin stimulated much higher phosphorylation of Erk in Lrp1- $\beta K O$ than in control islets. This stimulation completely depended on the availability of extracellular $\mathrm{Ca}^{2+}$ (Figure 5C and Supplemental Figure 5). Consistent with the data in freshly isolated islets (Figure 5, A and B, and Supplemental Figure 4), phosphorylation of S6K1, but not S6, follows the changes of Erk activation. Interestingly, the reduction in IRS-2 protein levels was observed in $L r p 1-\beta K O$ islets after high glucose treatment for 1 hour (Figure 5D and Supplemental Figure 6A), but not 15 minutes (Supplemental Figure 6,
$\mathrm{B}-\mathrm{F})$, suggesting time-dependent, progressive signal transduction from phosphorylated S6K1 to IRS-2 suppression, which is supported by a previous in vitro study (26).

Taken together, our data suggest that after HFD, $\beta$ cells require LRP1 to suppress the glucose-stimulated, $\mathrm{Ca}^{2+}$-dependent overactivation of Erk and p85 S6K1, thereby avoiding the inhibitory response during HFD exposure on insulin signaling mediated by molecules such as IRS-2.

Improved lipid metabolism in LRP1-deficient $\beta$ cells. LRP1 deficiency disrupts lipid metabolism in multiple tissues $(9-12,14)$. So we aimed to determine whether this is also a contributing factor to the impaired $\beta$ cell function and proliferation after HFD. Loss of LRP1 has been shown to cause apoE accumulation in mouse embryonic fibroblasts (MEFs) and neurons (11) as well as reduced apoE-lipoprotein secretion from liver (14). However, apoE levels were similar between control and $\operatorname{Lrp1}-\beta K O$ islets after HFD (Supplemental Figure 7, A, C-E). Defective lipid metabolism leads to increased lipotoxicity in $\beta$ cells, as indicated by the levels of ceramides, a group of sphingolipids (4). Surprisingly, we observed an overall decrease in ceramides in Lrp1- $\beta K O$ islets (Figure 6A). The same trends also existed in the lipotoxic precursors and derivatives of ceramides, including dihydro- (Figure 6B), lactosyl- (Figure 6C), and hexosyl-ceramides (Figure 6D), but not in sphingomyelins (Supplemental Figure 8A), the major storage form of sphingolipids or sphingoid bases (Supplemental Figure 8B), the early precursors and catabolites of ceramides. The normal levels of ceramide precursors and ceramide stores suggest that the levels of fatty acyl CoA, the fatty acid catabolites, may act as major determinants of ceramide levels in these $\beta$ cells. This is in support of the notion that the lipotoxic sphingolipid axis, dihydro-ceramides/ 
A

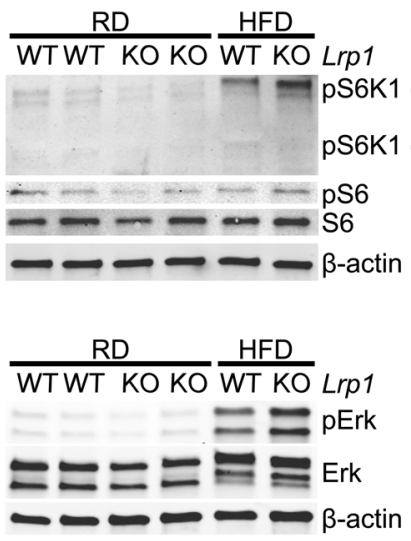

C

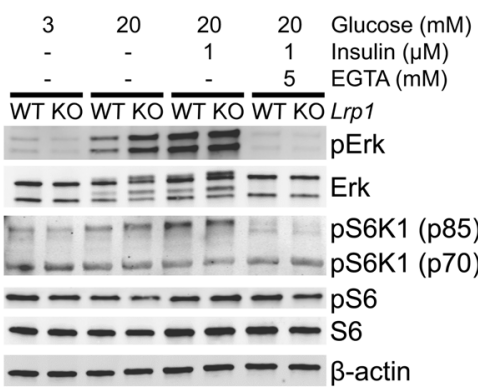

D
Figure 5. LRP1 controls Erk-mTORC1 activation and IRS-2 suppression in $\boldsymbol{\beta}$ cells. ( $\mathbf{A}$ and $\mathbf{B}$ ) Representative Western blots of mTORC1- (A) and Erk-signaling (B) molecules with pancreatic islets from mice 8 months after doxycycline treatment. (C and D) Overnight cultured islets from mice after 4 months of HFD were first quiesced in $\mathrm{SAB}$ with $3 \mathrm{mM}$ glucose and then treated with glucose, insulin, and EGTA at indicated concentrations for 15 minutes (C) or 1 hour (D). These islets were subjected to Western blotting of signaling molecules as indicated. Representative blots are presented. ceramides/lactosyl-ceramides/hexosyl-ceramides, are readouts of intracellular lipid metabolism (31). These data consistently indicate a mitigated level of lipotoxicity in $L r p 1-\beta K O$ islets compared with control islets after HFD.

To understand how LRP1 deficiency results in improved lipotoxicity in $\beta$ cells after HFD, we examined the expression of lipid metabolism genes and detected a significant induction in lipid enzymes Slc27a2 (Figure 7A), Cyp2c29, Cyp2c67, Cyp2d9 (Figure $7 \mathrm{~B}$ ), and $S c d 1$ (Figure $7 \mathrm{C}$ ). As for transcriptional regulators, FoxO1 expression was significantly reduced (Figure 7D). More to the point, there was a 3-fold increase in the mRNA of PPAR $\gamma 2$ isoform, but not the total PPAR $\gamma$ transcripts (Figure 7D). At the protein level, we observed that PPAR $\gamma 2$, but not PPAR $\gamma 1$, was induced in control islets by HFD and was further increased upon LRP1 ablation (Figure 7, E-G). In contrast, RD-fed Lrp1- $\beta K O$ mice displayed lower PPAR $\gamma$ levels in islets compared with controls, suggesting a different relationship between LRP1 and PPAR $\gamma$ under normal conditions relative to the DIO setting. These results suggest that the induction of $\operatorname{PPAR} \gamma 2$ may contribute, at least in part, to properly managing the lipid metabolism program in $L r p 1-\beta K O$ islets after HFD.

Acute overexpression of PPAR 2 impairs $\beta$ cell function and insulin signaling. To directly explore the role of intracellular lipid metabolism in $\beta$ cell function, we generated Pparg2- $\beta O E$, a mouse model enabling doxycycline-inducible, $\beta$ cell-specific expression of a FLAG-tagged mouse PPAR $\gamma 2$ protein (Figure 8A). Pparg2- $\beta O E$ (MIP-rtTA; TRE-Pparg2) mice and their control littermates (MIP$r t T A$ ) were fed on HFD for 4 months and then switched to doxycycline-containing HFD for 2 weeks. Both genotypes continued weight gain during these 2 weeks (Supplemental Figure 9A). Strikingly, Pparg2- $\beta O E$ mice, but not control mice, developed significant glucose intolerance after doxycycline treatment (Figure 8B). While control mice exhibited an adaptive increase in GSIS, Pparg2$\beta O E$ mice failed to do so (Figure 8C and Supplemental Figure 9B). Insulin-signaling proteins IR $\beta$, IRS- 2 , and Akt and their phosphorylated forms were reduced in Pparg2- $\beta O E$ islets compared with controls (Figure 8D and Supplemental Figure 10). However, this acute induction of PPAR $\gamma 2$ was not sufficient to change $\beta$ cell volume (Supplemental Figure 9C). Collectively, local overexpression of PPAR $\gamma 2$, the master transcriptional activator of lipid metabolism, simultaneously impairs $\beta$ cell insulin signaling and function, which recapitulates the response to LRP1 deficiency in the islet.
Elimination of Apbb2 impairs $\beta$ cell GSIS and systemic glucose tolerance. To obtain further mechanistic insights into how LRP1 regulates lipid metabolism and $\beta$ cell function, we wanted to further probe for a functional role of the LRP1 cytoplasmic domain, which directly interacts with multiple adaptor proteins and initiates cellular trafficking and signaling cascades (8). Apbb2 is a member of the amyloid $\beta$ (A4) precursor protein-binding family, which tethers amyloid precursor protein (APP) to the cytoplasmic domain of LRP1 $(32,33)$ to form potential scaffolds for protein complex assembly (34). We utilized a KO mouse model of Apbb2 and observed significant glucose intolerance even under RD feeding (Figure 9A), mimicking the Lrp1- $\beta K O$ phenotype after HFD (Figure 2D). When the isolated pancreatic islets were perifused with variable glucose concentrations, the $A p b b 2^{-/}$islets displayed blunted insulin secretion upon high glucose stimulation (Figure 9B). During the hyperglycemic clamp experiments, GSIS was intact in WTs, but almost abolished in Apbb2 $2^{-/}$mice (Figure 9C). Their defective glucose tolerance was also demonstrated by the higher circulating glucose levels (Figure 9D) and lower glucose infusion rate (Figure 9E) at the hyperglycemic stage. Interestingly, $A p b b 2^{--}$islets showed reduced mRNA (Supplemental Figure 11A), but normal protein (Supplemental Figure 11B) levels of LRP1, suggesting that function rather than the amount of LRP1 protein is regulated by Apbb2 in $\beta$ cell GSIS. Disruption of Apbb 2 may abolish the capacity of LRP1 to handle basal lipid flux and mimic its dysfunction upon HFD stress.

\section{Discussion}

As a member of the LDL receptor family, LRP1 plays highly diverse physiological roles in different tissues. It has been implicated in multiple human diseases, such as atherosclerosis, Alzheimer's disease, inflammation, and cancer (8). LRP1 modulates TGF- $\beta$ and PDGF $\beta$ signaling $(9,35,36)$ and regulates cholesterol export in vascular smooth muscle cells (37). In neurons, LRP1 supports insulin (38) and leptin (39) signaling, cellular glucose (40) and cholesterol uptake (11), and controls food intake. LRP1 is also critical for lipid transport and metabolism in adipocytes $(12,41,42)$. It improves the hepatic HDL/ LDL secretion ratio (43) and protects hepatocytes from lipotoxic insults (44). Based on these reports in the literature, LRP1 clearly performs unique functions in a cell type-specific way. It was, however, unclear what role LRP1 exerts in the context of the $\beta$ cell. Here, we 
A

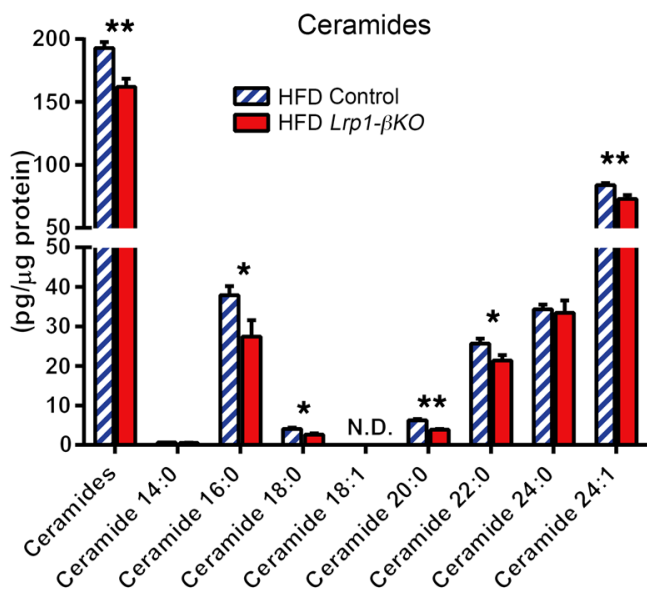

C
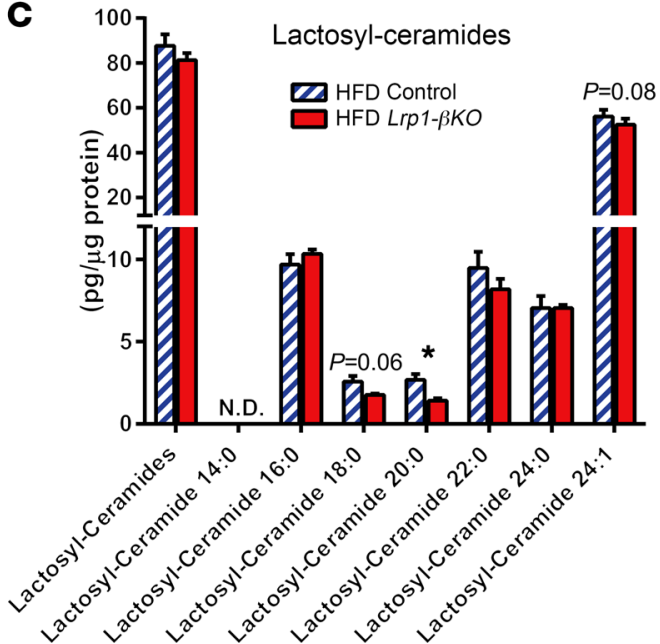

B

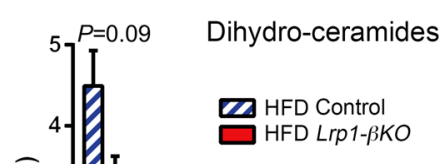

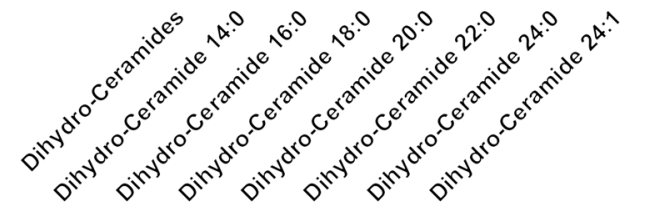

D

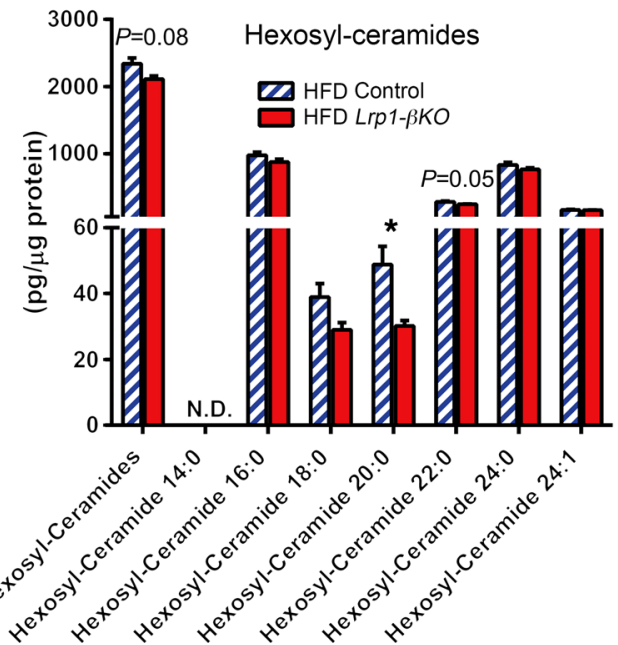

Figure 6. Reduced lipotoxic sphingolipids in HFD Lrp1- $\beta$ KO islets. Sphingolipids were assayed by mass spectrometry in pancreatic islets isolated from mice after doxycycline treatment and 8 months of HFD and normalized against the protein content of islet samples. $n=6$ (control) and $n=4(L r p 1-\beta K O)$ samples with 50 islets per sample. Sphingolipid species are categorized as (A) ceramides, (B) dihydro-ceramides, (C) lactosyl-ceramides, and (D) hexosylceramides. The furthest left columns in every panel represent the sum of all species evaluated. Data are presented as mean $\pm \mathrm{SEM}$. ${ }^{*} P<0.05$; ${ }^{* *} P<0.01$ for $L$ rp1- $\beta K O$ versus control by 2-tailed unpaired Student's $t$ test. ND, not detected.

unravel the critical role of LRP1 in $\beta$ cell adaptation to DIO and insulin resistance. High levels of glucose and lipids stimulate Erk, S6K1, and PPAR $\gamma 2$ signaling to enable the $\beta$ cells to manage the energy/nutrient surplus during DIO. As is the case for PDGFR $\beta$ and TGF- $\beta$ signaling in smooth muscle cells, the crucial function of LRP1 in islets is to moderate and prevent these signals from overactivation (Supplemental Figure 12A). In the absence of LRP1, the uncontrolled mTORC1 signaling and lipid metabolism programs both inhibit insulin signaling in the $\beta$ cells and eventually lead to a reduction in insulin production (Supplemental Figure 12B). So the basal levels of LRP1 act as an essential gatekeeper for $\beta$ cells during DIO. Two recent studies demonstrated LRP1 as a PPAR $\gamma$ coactivator in endothelial cells (45) and in macrophages (46). In contrast, in the context of the $\beta$ cell, we show here that LRP1 suppresses PPAR $\gamma 2$. These findings further underline the tissue-specific functions of LRP1. Alternatively, LRP1 may regulate PPAR $\gamma 2$ by spatially controlling its function. In the absence of LRP1, there could be a compensatory increase of PPAR $\gamma 2$ expression, which subsequently would deregulate other PPAR 2 -dependent pathways in a maladaptive manner. In either case, there seems to be a close regulatory relationship between LRP1 and PPAR $\gamma$.

With nutrient surplus, activation of maladaptive pathways may be a new mechanism by which glucolipotoxicity exerts its negative effects in $\beta$ cells. Previous studies showed in vitro that glucose activates Erk via an extracellular $\mathrm{Ca}^{2+}$ influx-dependent mechanism $(47,48)$. Erk can inhibit TSC2 and thus activate mTORC1 in parallel to Akt $(25,29)$. Activation of mTORC1 and S6K1 can inhibit insulin signaling in tissue culture or peripheral tissues (27, 49,50 ), although the molecular mechanisms remain controversial (51). Degradation of IRS-2 proteins can be a key component (26), since IRS- 2 is critical for $\beta$ cell compensation to insulin resistance $(52-57)$. For the first time, to our knowledge, our results link the axis of glucose $/ \mathrm{Ca}^{2+} / \mathrm{Erk} / \mathrm{mTORC} 1 / \mathrm{S} 6 \mathrm{~K} 1 / \mathrm{IRS}-2 /$ Akt in $\beta$ cells in vivo and demonstrate it as one of the mechanisms underlying the failed $\beta$ cell compensation in type 2 diabetes. 

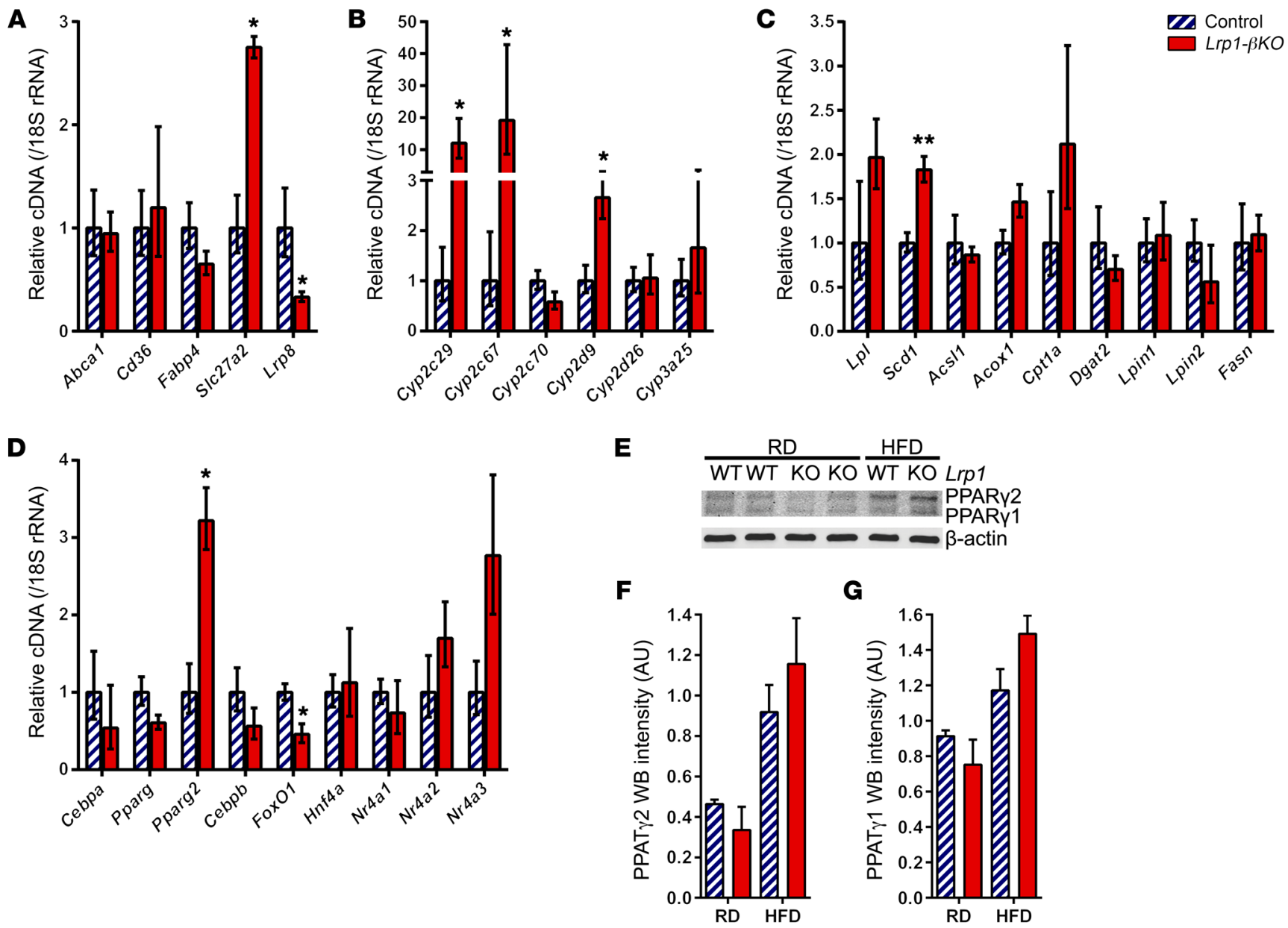

Figure 7. Improved lipid metabolism in HFD Lrp1- $\beta$ KO islets. Experiments used pancreatic islets from mice 8 months after doxycycline treatment. (A-D) RT-qPCR of lipid metabolism genes in the HFD groups. $n=3$ to 4 mice per genotype. Data are presented as mean \pm SEM. ${ }^{*} P<0.05$; ${ }^{* *} P<0.01$ for $L r p 1-\beta K O$ versus control by 2-tailed unpaired Student's $t$ test. (E-G) Representative Western blots (E) and quantitation (F and $\mathbf{G})$ of both PPAR $\gamma$ isoforms. $n=2$ mice per condition. Data are presented as mean \pm SEM.

On the other hand, DIO leads to an induction of PPAR $\gamma 2$, one of the master transcriptional activators of the lipid metabolism program in $\beta$ cells. In addition to combating intracellular lipotoxicity, PPAR $\gamma 2$ can impose inhibitory effects on $\beta$ cell insulin signaling and GSIS. We demonstrate this directly with the $\beta$ cell-specific overexpression mouse model. This can also provide more insights into the insulin-sparing effects of the thiazolidinediones (TZDs), which are PPAR $\gamma$ agonists (58). Activation of PPAR $\gamma$ in peripheral tissues, such as adipose tissue, can improve systemic lipid metabolism and insulin sensitivity through its beneficial effectors, e.g., adiponectin $(5,6)$. Meanwhile, TZDs will also activate PPAR $\gamma$ in $\beta$ cells and exert detrimental effects. These negative effects are at least partially suppressed by LRP1 action. Intriguingly, the complete ablation of PPAR $\gamma$ or PPAR $\gamma 2$ also prevents $\beta$ cell volume expansion in obesity (59, $60)$. This may explain the negative correlation between islet LRP1 levels and plasma insulin in B6:BTBR F2 $2^{o b / o b}$ mice. Taken together, these findings suggest that both the level and activity of PPAR $\gamma 2$ and its regulator LRP1 require tight control in $\beta$ cells during obesity in order to maintain a favorable balance between lipid metabolism and insulin signaling that allows for $\beta$ cell viability and adequate insulin production. Both excessive PPAR $\gamma 2$ in the absence of LRP1 and insufficient PPAR $\gamma 2$ in the presence of excessive LRP1 seem to be detrimental to $\beta$ cell viability and function. Doxycycline-inducible deletion or overexpression mouse models will allow fine tuning of LRP1 levels in $\beta$ cells and a more subtle dissection of the mechanistic changes. These experiments await future investigation.

The $\beta$ cell requirement on LRP1 under HFD but not RD regimens provides mechanistic clues for LRP1 function. The damage control mechanisms of LRP1 upon glucolipotoxicity may not be needed or applicable when nutrient flux is normal. Another possibility is that LRP1 function is relevant, but redundant under RD. In contrast, Apbb2 KO results in defective GSIS in RD-fed mice, suggesting a fundamental role in $\beta$ cell physiology. Apbb1, -2 , and -3 are members of a group of proteins linking APP to the cytoplasmic domain of LRP1 $(32,33)$, and APP interacts with cholesterol metabolism in neurons (61). Ablation of Apbb2 may disrupt, not only the potential role of LRP1 in cholesterol metabolism, but also the molecular scaffolds containing LRP1 and APP, assembling protein complexes (34) and initiating pleiotropic intracellular signaling pathways. We speculate that targeted mutations of the LRP1 cytoplasmic domain will shed light on the molecular interactions critical for $\beta$ cell function. 
A
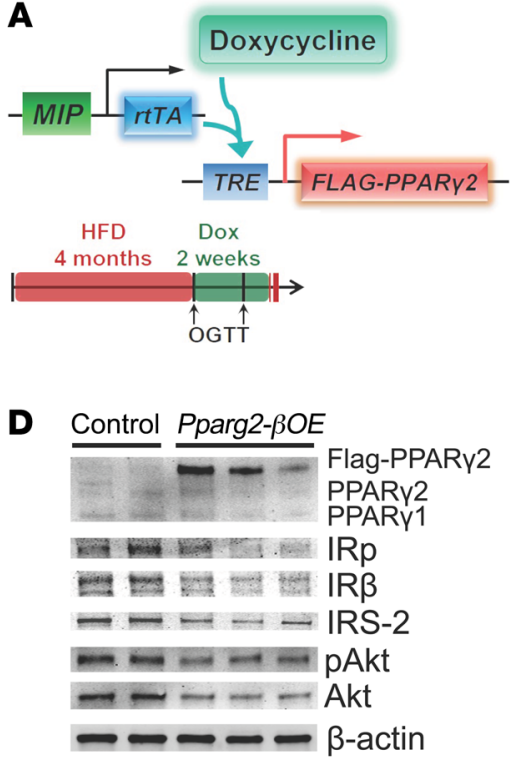

B

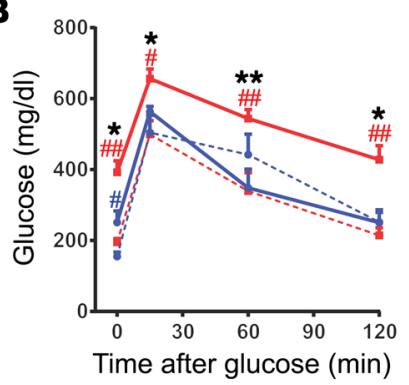

C

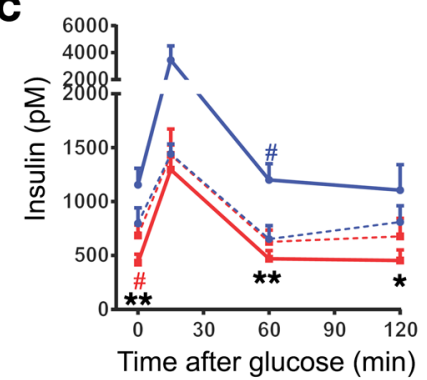

Figure 8. PPAR $\boldsymbol{\gamma} 2$ overexpression impairs GSIS and insulin signaling in $\boldsymbol{\beta}$ cells after HFD. (A) Doxycycline-inducible overexpression of FLAG-tagged PPAR $\gamma 2$ in mouse $\beta$ cells. After 4 months of HFD, both Pparg2- $\beta O E$ and control mice were switched to doxycycline HFD. Mice were subjected to oral glucose tolerance test (OGTT) (2 mg/g body weight) before and 2 weeks after doxycycline HFD. (B and C) Plasma glucose (B) and insulin (C) during oral glucose tolerance test. $n=4$ (control) and $n=7$ (Pparg2- $\beta O E$ ) mice. Data are presented as mean \pm SEM. ${ }^{*} P<0.05$; ${ }^{*} P<0.01$ for $P$ parg2- $\beta 0 E$ versus control mice; ${ }^{\#} P<0.05 ;{ }^{\# \#} P<0.01$ for before versus after doxycycline by 2 -tailed unpaired Student's $t$ test. (D) Representative Western blots of insulin-signaling molecules with islets from mice after 3 weeks of doxycycline HFD.

\section{Methods}

Mice. B6 and BTBR mice were intercrossed to generate the F2 cohort carrying the Leptin ${ }^{o b / o b}$ alleles by the Attie laboratory (62). The Lrp1 floxed $\left(\operatorname{Lrp} 1^{f / f l}\right)$ mouse strain was generated by the Herz laboratory (16). MIP-rtTA was generated by the Scherer laboratory $(17,63)$. TRECre was purchased from the Jackson Laboratory (catalog 006234). TRE-Pparg 2 was recently generated by the Gupta laboratory. The

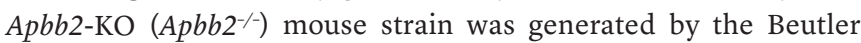
laboratory using the CRISPR system. Female C57BL/6J mice were superovulated by injection with $6.5 \mathrm{U}$ pregnant mare serum gonadotropin (PMSG) (Millipore), then $6.5 \mathrm{U}$ human chorionic gonadotropin (hCG) (Sigma-Aldrich) 48 hours later. The superovulated mice were subsequently mated with $\mathrm{C} 57 \mathrm{BL} / 6 \mathrm{~J}$ male mice overnight. The following day, fertilized eggs were collected from the oviducts and in vitro transcribed Cas9 mRNA (50 ng/ $\mu \mathrm{l})$ and Apbb2 small baseparing guide RNA (5'-CGGAGATTGAGGGTATTTGG-3', $50 \mathrm{ng} /$ $\mu l)$ were injected into the pronucleus of the embryos. The injected embryos were cultured in M16 medium (Sigma-Aldrich) at $37^{\circ} \mathrm{C}$ and $95 \%$ air $/ 5 \% \mathrm{CO}_{2}$. For the production of mutant mice, 2-cell stage embryos were transferred into the ampulla of the oviduct (10-20 embryos per oviduct) of pseudopregnant Hsd:ICR (CD-1) (Harlan Laboratories) females. The $\operatorname{Lrp} 1^{f l f l}$ strain was maintained at a mixed genetic background of 129/sv, FVB, and C57BL/6, while all the other strains were bred on a C57BL/6 genetic background. Mice were housed on a 12-hour dark/12-hour light cycle, with ad libitum access to water and diet. Diets used in this study included RD (LabDiet, catalog 5058; Purina catalog 5008), doxycycline chow diet (600 $\mathrm{mg} / \mathrm{kg}$; Bio-Serv, catalog S7123), HFD (60\% calorie from fat; BioServ, catalog S1850), and doxycycline HFD (600 mg/kg, 60\% calorie from fat; Bio-Serv, catalog S5867). Only male mice were used in the HFD experiments, as female mice show a sexually dimorphic response in HFD-induced obesity and insulin resistance. Body composition was measured with a Bruker Minispec mq10 analyzer. Genotyping PCR was performed with tail DNA. The conditions are detailed in Supplemental Methods.

B6:BTBR F $2^{\text {ob/ob }}$ mouse islet profiling. Male and female 10-week-old chow-fed B6:BTBR F $2^{o b / o b}$ mice were assessed for fasting plasma glucose and triglyceride and insulin levels as well as gene expression in isolated islets with microarray analysis, as previously described (64). Mice were maintained on chow diet for 10 weeks prior to analysis.

Islet isolation and culture. Mouse islets were isolated via collagenase digestion of exocrine pancreas as previously described (5). Freshly isolated islets were either snap-frozen with liquid nitrogen followed by $-80^{\circ} \mathrm{C}$ storage for mRNA, protein, and sphingolipid analyses or pooled by genotypes and transferred to RPMI 1640 medium with $10 \%$ FBS, $1 \%$ antibiotics, 5 mM glucose, 2 mM GlutaMAX-I (Gibco, Thermo Fisher Scientific, catalog 35050-061), and 0.2\% BSA for overnight culture. For signal transduction experiments, the overnight-cultured islets were first quiesced in secretion assay buffer (SAB) $(137 \mathrm{mM} \mathrm{NaCl}$, $4.7 \mathrm{mM} \mathrm{KCl}, 1.2 \mathrm{mM} \mathrm{KH}_{2} \mathrm{PO}_{4}, 1.2 \mathrm{mM} \mathrm{MgSO}_{4}, 20$ mM HEPES, $25 \mathrm{mM}$ $\mathrm{NaHCO}_{3}, 2.5 \mathrm{mM} \mathrm{CaCl}_{2}, 0.2 \% \mathrm{BSA}, \mathrm{pH}$ 7.2) with $3 \mathrm{mM}$ dextrose for 1.5 hours. Next, islets (approximately 50-80) were transferred to 6 wells containing $2 \mathrm{ml}$ of SAB with $3 \mathrm{mM}$ dextrose and quiesced for another 1 hour. For signal stimulation, islets were then transferred to 6 wells containing SAB with specified supplements and incubated for $15 \mathrm{~min}$ utes or 1 hour. After incubation, islets were snap-frozen with liquid nitrogen and stored at $-80^{\circ} \mathrm{C}$ for Western blotting.

$R T-q P C R$. The isolated islets were processed for reverse transcription (RT) and quantitative real-time PCR (qPCR) as described previously (6). Primer sequences are in Supplemental Table 1. 

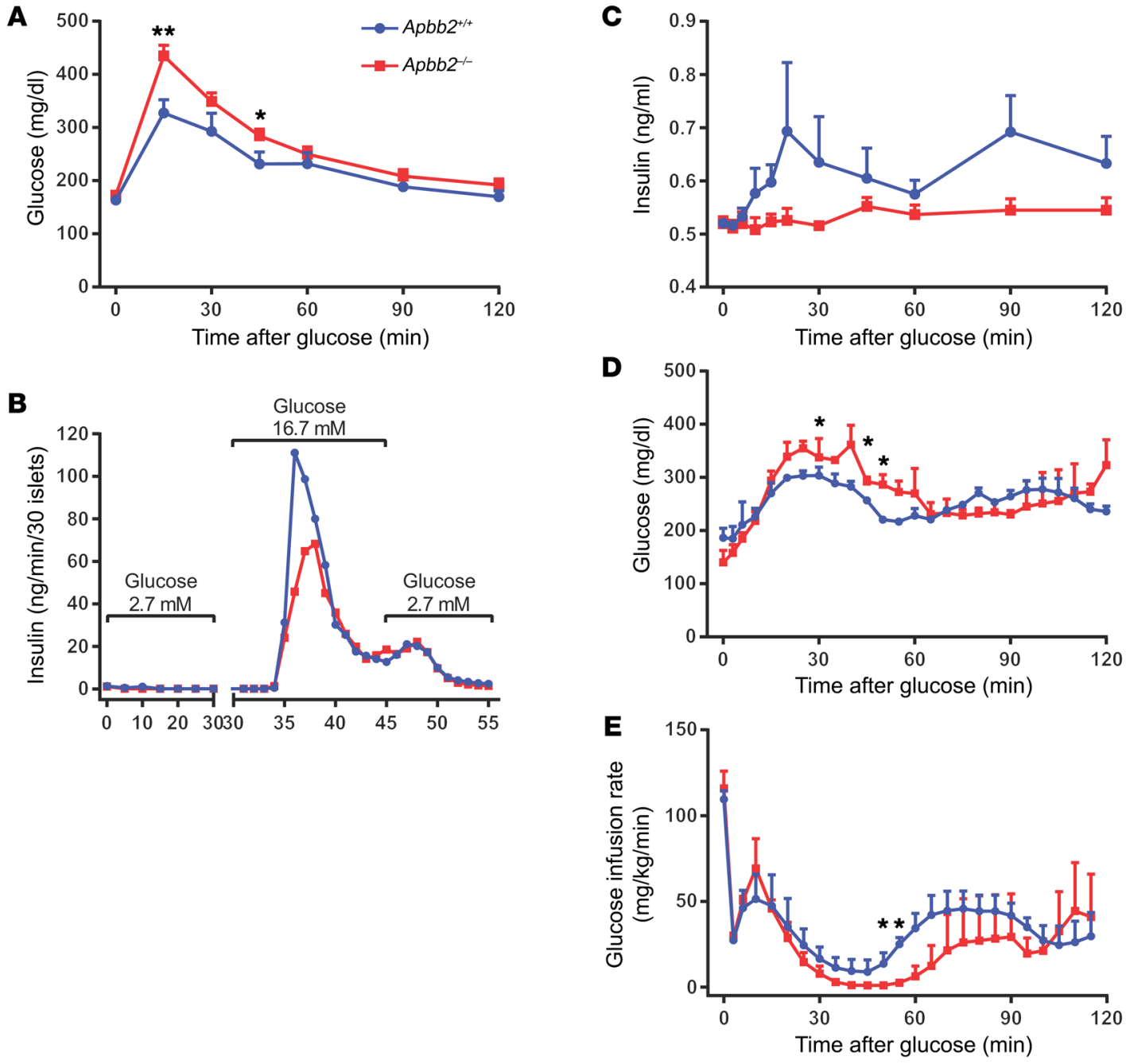

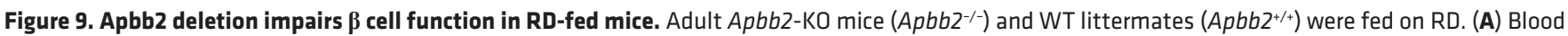
glucose during i.p. glucose tolerance test $\left(1 \mathrm{mg} / \mathrm{g}\right.$ body weight). $n=6\left(A p b b 2^{+/+}\right)$and $n=9\left(A p b b 2^{-/-}\right)$mice. (B) Thirty islets per genotype were subjected to perifusion with glucose concentration at $2.7 \mathrm{mM}$ (0-30 minutes), $16.7 \mathrm{mM}$ (30-45 minutes), and $2.7 \mathrm{mM}$ (45-55 minutes). Insulin concentrations of perifusion fractions were assayed and presented. (C-E) Plasma insulin (C), blood glucose (D), and glucose infusion rate (E) during hyperglycemic clamp. $n=3$ mice per genotype. Data are presented as mean \pm SEM. ${ }^{*} P<0.05 ;^{* *} P<0.01$ for Apbb2-/- versus Apbb2 ${ }^{+/+}$mice by 2 -tailed unpaired Student's $t$ test.

Western blotting. To prepare protein lysates, $1 \times$ SDS loading buffer (50 mM Tris-Cl, pH 6.8, 100 mM DTT, 2\% SDS, 10\% glycerol, $0.005 \%$ bromophenol blue) was added to the snap-frozen islets and incubated at $95^{\circ} \mathrm{C}$ for 10 minutes. As previously described (5), protein separation and transfer were performed with 4\%-15\% Mini-PROTEAN TGX Gels (BioRad, catalog 456-1086), Trans-Blot Turbo Mini Nitrocellulose Transfer Packs (Bio-Rad, catalog 170-4158), and the Trans-Blot Turbo Transfer Starter System (Bio-Rad, catalog 170-4155). Primary antibodies included LRP1 (rabbit polyclonal 377, Herz laboratory) (65), $\beta$-actin (Novus, catalog NB600-501), IR $\beta$ (Santa Cruz Biotechnology Inc., catalog sc-711), IRS-2 (Upstate, catalog 06-506), pSer473-Akt (Cell Signaling Technology, catalog 9271), Akt (Cell Signaling Technology, catalog 9272), pSer133-CREB (Cell Signaling Technology, catalog 9198), CREB (Cell Signaling Technology, catalog 9197), pThr389-S6K1 (Cell Signaling Technology, catalog 9206), pSer235-S6 (Cell Signaling Technology, catalog 4856), S6 (Cell Signaling Technology, catalog 2217), pThr202/Tyr204-Erk (Cell Signaling Technology, catalog 4370), Erk (Cell Signaling Technology, catalog 4695), PDGFR $\beta$ (Santa Cruz Biotechnology Inc., catalog sc-432), apoE
(Santa Cruz Biotechnology Inc., catalog sc-6384), PPAR $\gamma$ (Cell Signaling Technology, catalog 2435), and GAPDH (Cell Signaling Technology, cata$\log 2118)$. Immunoblots were imaged on an Odyssey CLx infrared imaging system (LI-COR) and quantitated with ImageJ Gel Analyzer (NIH).

Immunohistochemistry. Mouse pancreata were harvested and processed for paraffin sections as previously described (5). For BrdU incorporation, mice were subjected to 3 consecutive daily i.p. injections of BrdU (100 $\mu \mathrm{g} / \mathrm{g}$ BDW) before sacrifice. Primary antibodies used for immunostaining or immunofluorescence were as follows: insulin (Dako, catalog A0564), LRP1 (Herz laboratory), glucagon (Invitrogen, catalog 18-0064; Abcam, catalog ab10988), BrdU (AbD Serotec, catalog MCA2060), IR $\beta$ (Santa Cruz Biotechnology Inc., catalog sc-711), pThr389-S6K1 (Cell Signaling Technology, catalog 9206), and apoE (Santa Cruz Biotechnology Inc., catalog sc-6384). $\beta$ Cell areas were quantitated by whole-slide scanning as previously described (5). Images were acquired on a Zeiss Axio Observer Z1 inverted microscope or an Olympus FSX100 all-in-one microscope. Fluorescence intensity and area were quantitated with ImageJ. 
Glucose tolerance test. Mice were fasted for 4 to 6 hours and subjected to an oral gavage or i.p. injection of dextrose. Tail blood was collected at multiple time points and prepared for plasma. Glucose was assayed with a glucose meter or PGO enzymes (Sigma-Aldrich, catalog P7119) plus o-Dianisidine (Sigma-Aldrich, catalog F5803). Insulin was measured with ELISA kits (Crystal Chem, catalog 90080).

Transmission electron microscopy. Under isoflurane anesthesia, mice were subjected to cardiac perfusion of a perfusion buffer (4\% paraformaldehyde, $1 \%$ glutaraldehyde, $0.1 \mathrm{M}$ sodium cacodylate, $\mathrm{pH}$ 7.4). Pancreata were dissected, transferred to fixative (2.5\% glutaraldehyde, 0.1 M sodium cacodylate, $\mathrm{pH}$ 7.4), minced to less than $1 \mathrm{~mm}$ pieces, and then processed at the UTSW Electron Microscopy Core Facility. Sections were examined with a JEOL 1200 EX electron microscope and photographed with a Sis Morada 11 MegaPixel side-mounted CCD camera.

Sphingolipid assays by mass spectrometry. Snap-frozen islets were assayed for sphingolipid species at the UTSW Metabolic Phenotyping Core as previously described (5).

GSIS on perfused pancreata. Perfusions were performed as described (63). In brief, mouse pancreata were perfused with buffers containing either $2.7 \mathrm{mM}$ glucose or $16.7 \mathrm{mM}$ glucose (Sigma-Aldrich). All buffers before reaching the celiac artery were maintained at $37^{\circ} \mathrm{C}$. Perfusates were then collected at 1-minute intervals for 25 minutes. Insulin levels were measured in perfusates using an insulin assay kit (Cisbio US Inc.).

Hyperglycemic clamp studies. Chronic indwelling catheters were aseptically placed in the right jugular vein, and hyperglycemic clamps were performed on conscious, unrestrained mice as we have previously described (66). Briefly, body weight-, and age-matched animals were fasted for 3 hours prior to a variable glucose infusion rate to increase and maintain blood glucose at approximately $260 \mathrm{mg} / \mathrm{dl}$. Tail blood glucose was measured at $0,3,6$, and 10 minutes and then every 5 minutes until 120 minutes. Blood samples to measure plasma insulin were taken at $0,3,6,10,15,20,30,45,60,90$, and 120 minutes.

Statistics. Kolmogorov-Smirnov test with Lilliefors correction was applied for data normality. Pearson product moment test was applied for correlation. Two-tailed Student's $t$ test was applied for all pairwise comparisons unless indicated. Statistical significance was defined as $P<0.05$.

Study approval. All protocols for mouse use and euthanasia were reviewed and approved by the Institutional Animal Care and Use Committee of the UTSW Medical Center and the University of Wisconsin Research Animal Resource Center.

\section{Author contributions}

RY designed and conducted experiments, acquired and analyzed data, and wrote the manuscript. RG conducted experiments and acquired and analyzed data. MS provided reagents and analyzed data. TO and ZC conducted experiments and acquired and analyzed data. SC and X Lin conducted experiments and acquired data. JAS, X Li, and MT conducted experiments and acquired and analyzed data. MPK conducted experiments and acquired and analyzed data. RK planned and conducted experiments and acquired and analyzed data. ADA designed experiments and analyzed data. RKG provided reagents and analyzed data. WLH designed and conducted experiments, acquired and analyzed data, and wrote the manuscript. BB designed experiments and analyzed data. JH provided reagents and analyzed data. PES conceptualized the studies, designed experiments, analyzed data, and wrote the manuscript.

\section{Acknowledgments}

We thank Xunde Xian and Yinyuan Ding for helpful discussion. We thank the UTSW Mouse Phenotyping Core for metabolic assays and mass spectrometry and the UTSW Electron Microscopy Core and Molecular Pathology Core for tissue embedding and processing. This study was supported by the NIH (grants R01-DK55758, R01-DK099110, and P01-DK088761-01 to PES; R01-DK101573 and R01-DK102948 to ADA) and the Juvenile Diabetes Research Foundation (JDRF 17-2012-36 to PES and 2-SRA-2016-149-Q-R to PES and WLH). PES was also supported by an unrestricted grant from the Novo Nordisk Research Foundation. RY was supported with a research fellowship from the Naomi Berrie Diabetes Center, Columbia University Medical Center. JH is supported by grants from the National Heart, Lung, and Blood Institute (NHLBI) (R37HL63762), the National Institute of Neurological Disorders and Stroke (NINDS) (R01 NS093382), NINDS and the National Institute on Aging (NIA) (RF AG053391), the Brightfocus Foundation, and the Bluefield Project. JAS was supported by a Howard Hughes Medical Institute research fellowship.

Address correspondence to: Philipp E. Scherer, 5323 Harry Hines Boulevard, Dallas, Texas 75390-8549, USA. Phone: 214.648.8715; Email: philipp.scherer@utsouthwestern.edu.
1. Linnemann AK, Baan M, Davis DB. Pancreatic $\beta$-cell proliferation in obesity. Adv Nutr. 2014;5(3):278-288.

2. Leibiger IB, Leibiger B, Berggren PO. Insulin signaling in the pancreatic beta-cell. Annu Rev Nutr. 2008;28:233-251.

3. Poitout V, Amyot J, Semache M, Zarrouki B, Hagman D, Fontés G. Glucolipotoxicity of the pancreatic beta cell. Biochim Biophys Acta. 2010;1801(3):289-298.

4. Holland WL, et al. Receptor-mediated activation of ceramidase activity initiates the pleiotropic actions of adiponectin. Nat Med. 2011;17(1):55-63.

5. Ye R, et al. Adiponectin is essential for lipid homeostasis and survival under insulin deficiency and promotes $\beta$-cell regeneration. Elife. 2014;3:e03851.

6. Ye R, Wang M, Wang QA, Scherer PE. Adiponectin-mediated antilipotoxic effects in regenerating pancreatic islets. Endocrinology. 2015;156(6):2019-2028.
7. Herz J, Hamann U, Rogne S, Myklebost O, Gausepohl H, Stanley KK. Surface location and high affinity for calcium of a 500-kd liver membrane protein closely related to the LDL-receptor suggest a physiological role as lipoprotein receptor. ЕМВО J.1988;7(13):4119-4127.

8. Lillis AP, Van Duyn LB, Murphy-Ullrich JE, Strickland DK. LDL receptor-related protein 1: unique tissue-specific functions revealed by selective gene knockout studies. Physiol Rev. 2008;88(3):887-918.

9. Boucher P, Gotthardt M, Li WP, Anderson RG, Herz J. LRP: role in vascular wall integrity and protection from atherosclerosis. Science. 2003;300(5617):329-332.

10. May P, et al. Neuronal LRP1 functionally associates with postsynaptic proteins and is required for normal motor function in mice. Mol Cell Biol. 2004;24(20):8872-8883.

11. Liu Q, et al. Amyloid precursor protein regulates brain apolipoprotein E and cholesterol metabolism through lipoprotein receptor LRP1. Neuron. 2007;56(1):66-78.

12. Hofmann SM, et al. Adipocyte LDL receptorrelated protein-1 expression modulates postprandial lipid transport and glucose homeostasis in mice. J Clin Invest. 2007;117(11):3271-3282.

13. Rohlmann A, Gotthardt M, Hammer RE, Herz J. Inducible inactivation of hepatic LRP gene by cre-mediated recombination confirms role of LRP in clearance of chylomicron remnants. JClin Invest. 1998;101(3):689-695.

14. Ding Y, Xian X, Holland WL, Tsai S, Herz J. Lowdensity lipoprotein receptor-related protein-1 protects against hepatic insulin resistance and hepatic Steatosis. EBioMedicine. 2016;7:135-145.

15. Stoehr JP, et al. Genetic obesity unmasks nonlinear interactions between murine type 2 diabetes susceptibility loci. Diabetes. 2000;49(11):1946-1954. 
16. Rohlmann A, Gotthardt M, Willnow TE, Hammer RE, Herz J. Sustained somatic gene inactivation by viral transfer of Cre recombinase. Nat Biotechnol.1996;14(11):1562-1565.

17. Ye R, et al. Autonomous interconversion between adult pancreatic $\alpha$-cells and $\beta$-cells after differential metabolic challenges. Mol Metab. 2016;5(7):437-448.

18. Moll UM, Petrenko O. The MDM2-p53 interaction. Mol Cancer Res. 2003;1(14):1001-1008.

19. Zhou Y, et al. TCF7L2 is a master regulator of insulin production and processing. $\mathrm{Hum} \mathrm{Mol}$ Genet. 2014;23(24):6419-6431.

20. Kulkarni RN, Jhala US, Winnay JN, Krajewski S, Montminy M, Kahn CR. PDX-1 haploinsufficiency limits the compensatory islet hyperplasia that occurs in response to insulin resistance. JClin Invest. 2004;114(6):828-836.

21. Gu C, et al. Pancreatic beta cells require NeuroD to achieve and maintain functional maturity. Cell Metab. 2010;11(4):298-310.

22. Shimobayashi M, Hall MN. Making new contacts: the mTOR network in metabolism and signalling crosstalk. Nat Rev Mol Cell Biol. 2014;15(3):155-162.

23. Pende M, et al. S6K1(-/-)/S6K2(-/-) mice exhibit perinatal lethality and rapamycin-sensitive 5'-terminal oligopyrimidine mRNA translation and reveal a mitogen-activated protein kinasedependent S6 kinase pathway. Mol Cell Biol. 2004;24(8):3112-3124.

24. Xie J, El Sayed NM, Qi C, Zhao X, Moore CE, Herbert TP. Exendin-4 stimulates islet cell replication via the IGF1 receptor activation of mTORC1/ S6K1. JMol Endocrinol. 2014;53(1):105-115.

25. Song MS, Salmena L, Pandolfi PP. The functions and regulation of the PTEN tumour suppressor. Nat Rev Mol Cell Biol. 2012;13(5):283-296.

26. Briaud I, Dickson LM, Lingohr MK, McCuaig JF, Lawrence JC, Rhodes CJ. Insulin receptor substrate-2 proteasomal degradation mediated by a mammalian target of rapamycin (mTOR)induced negative feedback down-regulates protein kinase B-mediated signaling pathway in beta-cells. J Biol Chem. 2005;280(3):2282-2293.

27. Manning BD. Balancing Akt with S6K: implications for both metabolic diseases and tumorigenesis. J Cell Biol. 2004;167(3):399-403.

28. Leibowitz G, Cerasi E, Ketzinel-Gilad M. The role of $\mathrm{mTOR}$ in the adaptation and failure of beta-cells in type 2 diabetes. Diabetes Obes Metab. 2008;10 Suppl 4:157-169.

29. Ma L, Chen Z, Erdjument-Bromage H, Tempst P, Pandolfi PP. Phosphorylation and functional inactivation of TSC2 by Erk implications for tuberous sclerosis and cancer pathogenesis. Cell. 2005;121(2):179-193.

30. Winter JN, Jefferson LS, Kimball SR. ERK and Akt signaling pathways function through parallel mechanisms to promote mTORC1 signaling. Am J Physiol, Cell Physiol. 2011;300(5):C1172-C1180.

31. Ogretmen B, Hannun YA. Biologically active sphingolipids in cancer pathogenesis and treatment. Nat Rev Cancer. 2004;4(8):604-616.

32. Kinoshita A, Shah T, Tangredi MM, Strickland DK, Hyman BT. The intracellular domain of the low density lipoprotein receptor-related protein modulates transactivation mediated by amyloid precursor protein and Fe65.J Biol Chem.
2003;278(42):41182-41188.

33. Carter CJ. Convergence of genes implicated in Alzheimer's disease on the cerebral cholesterol shuttle: APP, cholesterol, lipoproteins, and atherosclerosis. Neurochem Int. 2007;50(1):12-38.

34. Trommsdorff M, Borg JP, Margolis B, Herz J. Interaction of cytosolic adaptor proteins with neuronal apolipoprotein $\mathrm{E}$ receptors and the amyloid precursor protein. J Biol Chem . 1998;273(50):33556-33560.

35. Boucher P, et al. LRP1 functions as an atheroprotective integrator of TGFbeta and PDFG signals in the vascular wall: implications for Marfan syndrome. PLoS One. 2007;2(5):e448.

36. Zhou L, Takayama Y, Boucher P, Tallquist MD, Herz J. LRP1 regulates architecture of the vascular wall by controlling PDGFRbeta-dependent phosphatidylinositol 3-kinase activation. PLoS One. 2009;4(9):e6922.

37. Zhou L, Choi HY, Li WP, Xu F, Herz J. LRP1 controls cPLA2 phosphorylation, ABCA1 expression and cellular cholesterol export. PLoS One. 2009;4(8):e6853.

38. Fuentealba RA, Liu Q, Kanekiyo T, Zhang J, Bu G. Low density lipoprotein receptor-related protein 1 promotes anti-apoptotic signaling in neurons by activating Akt survival pathway. J Biol Chem. 2009;284(49):34045-34053.

39. Liu Q, et al. Lipoprotein receptor LRP1 regulates leptin signaling and energy homeostasis in the adult central nervous system. PLoS Biol. 2011;9(1):e1000575.

40. Liu CC, et al. Neuronal LRP1 regulates glucose metabolism and insulin signaling in the brain. J Neurosci. 2015;35(14):5851-5859.

41. Masson O, et al. LRP1 receptor controls adipogenesis and is up-regulated in human and mouse obese adipose tissue. PLoS One. 2009;4(10):e7422.

42. Terrand J, et al. LRP1 controls intracellular cholesterol storage and fatty acid synthesis through modulation of Wnt signaling. J Biol Chem. 2009;284(1):381-388.

43. Basford JE, et al. Hepatic deficiency of low density lipoprotein receptor-related protein-1 reduces high density lipoprotein secretion and plasma levels in mice. J Biol Chem. 2011;286(15):13079-13087.

44. Hamlin AN, Basford JE, Jaeschke A, Hui DY. LRP1 protein deficiency exacerbates palmitateinduced steatosis and toxicity in hepatocytes. J Biol Chem. 2016;291(32):16610-16619.

45. Mao H, et al. Endothelial LRP1 regulates metabolic responses by acting as a co-activator of PPAR $\gamma$. Nat Commun. 2017;8:14960.

46. Xian X, et al. LRP1 integrates murine macrophage cholesterol homeostasis and inflammatory responses in atherosclerosis. eLife. 2017;6:e29292.

47. Khoo S, Cobb MH. Activation of mitogen-activating protein kinase by glucose is not required for insulin secretion. Proc Natl Acad Sci USA. 1997;94(11):5599-5604.

48. Fei H, Zhao B, Zhao S, Wang Q. Requirements of calcium fluxes and ERK kinase activation for glucose- and interleukin-1beta-induced beta-cell apoptosis. Mol Cell Biochem. 2008;315(1-2):75-84.

49. Tremblay F, et al. Overactivation of S6 kinase 1 as a cause of human insulin resistance during increased amino acid availability. Diabetes. 2005;54(9):2674-2684.
50. Veilleux A, Houde VP, Bellmann K, Marette A. Chronic inhibition of the mTORC1/S6K1 pathway increases insulin-induced PI3K activity but inhibits Akt2 and glucose transport stimulation in 3T3-L1 adipocytes. Mol Endocrinol. 2010;24(4):766-778.

51. Copps KD, Hancer NJ, Opare-Ado L, Qiu W, Walsh C, White MF. Irs1 serine 307 promotes insulin sensitivity in mice. Cell Metab. 2010;11(1):84-92.

52. Kubota N, et al. Disruption of insulin receptor substrate 2 causes type 2 diabetes because of liver insulin resistance and lack of compensatory betacell hyperplasia. Diabetes. 2000;49(11):1880-1889.

53. Withers DJ, Burks DJ, Towery HH, Altamuro SL, Flint CL, White MF. Irs-2 coordinates Igf-1 receptor-mediated beta-cell development and peripheral insulin signalling. Nat Genet. 1999;23(1):32-40.

54 . Kubota N, et al. Insulin receptor substrate 2 plays a crucial role in beta cells and the hypothalamus. J Clin Invest. 2004;114(7):917-927.

55. Choudhury AI, et al. The role of insulin receptor substrate 2 in hypothalamic and beta cell function. JClin Invest. 2005;115(4):940-950.

56. Assmann A, Ueki K, Winnay JN, Kadowaki T, Kulkarni RN. Glucose effects on beta-cell growth and survival require activation of insulin receptors and insulin receptor substrate 2. Mol Cell Biol. 2009;29(11):3219-3228.

57. Stamateris RE, et al. Glucose induces mouse $\beta$-cell proliferation via IRS2, MTOR, and Cyclin D2 but not the insulin receptor. Diabetes. 2016;65(4):981-995.

58. Bollheimer LC, Troll S, Landauer H, Wrede CE, Schölmerich J, Buettner R. Insulin-sparing effects of troglitazone in rat pancreatic islets. JMol Endocrinol. 2003;31(1):61-69.

59. Rosen ED, et al. Targeted elimination of peroxisome proliferator-activated receptor gamma in beta cells leads to abnormalities in islet mass without compromising glucose homeostasis. Mol Cell Biol. 2003;23(20):7222-7229.

60. Medina-Gomez G, et al. PPAR gamma 2 prevents lipotoxicity by controlling adipose tissue expandability and peripheral lipid metabolism. PLoS Genet. 2007;3(4):e64.

61. Pierrot N, et al. Amyloid precursor protein controls cholesterol turnover needed for neuronal activity. EMBO Mol Med. 2013;5(4):608-625.

62. $\mathrm{Tu} \mathrm{Z}$, et al. Integrative analysis of a cross-loci regulation network identifies App as a gene regulating insulin secretion from pancreatic islets. PLoS Genet. 2012;8(12):e1003107.

63. Kusminski CM, et al. MitoNEET-Parkin effects in pancreatic $\alpha$ - and $\beta$-cells, cellular survival, and intrainsular cross talk. Diabetes. 2016;65(6):1534-1555.

64. Keller MP, et al. The transcription factor Nfatc2 regulates $\beta$-cell proliferation and genes associated with type 2 diabetes in mouse and human islets. PLoS Genet. 2016;12(12):e1006466.

65. Ishibashi S, Brown MS, Goldstein JL, Gerard RD, Hammer RE, Herz J. Hypercholesterolemia in low density lipoprotein receptor knockout mice and its reversal by adenovirus-mediated gene delivery. J Clin Invest. 1993;92(2):883-893.

66. Chen Z, et al. Mutation of mouse Samd 4 causes leanness, myopathy, uncoupled mitochondrial respiration, and dysregulated mTORC1 signaling. Proc Natl Acad Sci USA. 2014;111(20):7367-7372. 